\title{
AGENTES DE INFECCIONES POR HONGOS DIMORFICOS Y Cryptococcus neoformans
}

\author{
AGENTS BY DIMORPHIC FUNGI AND \\ Cryptococcus neoformans INFECTIONS
}

Rito Zerpa ${ }^{1,2, a}$, Vilma Béjar ${ }^{2, b}$, Roberto Rojas $2, \mathrm{c}$

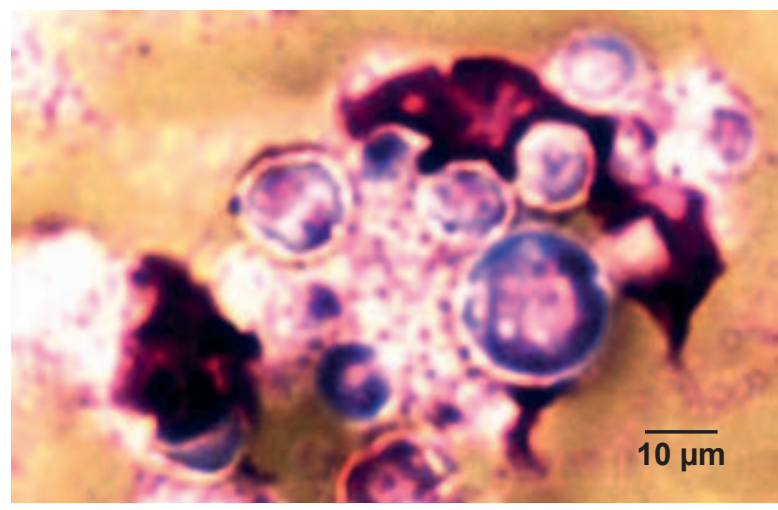

Figura 1. Paracoccidioides brasiliensis, microfotografía de secreción de ganglio, teñido con Giemsa. Se observa levaduras azuladas de diferente tamaño.

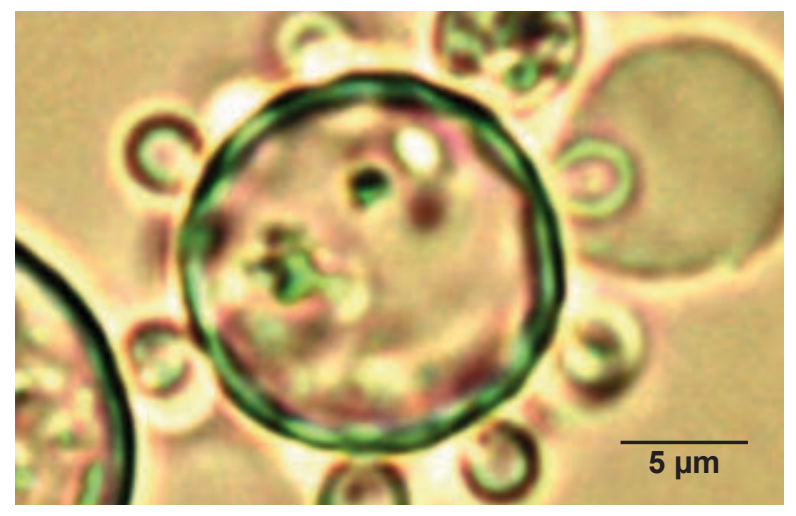

Figura 2. Paracoccidioides brasiliensis, microfotografía de preparación en fresco a partir de cultivo en agar sangre $\mathrm{BHI}$ a $35^{\circ} \mathrm{C}$. Se observa levadura multigemante en timón de barco.

Se presentan microfotografías de hongos dimórficos: Histoplasma capsulatum, Paracoccidiodes brasiliensis, causantes de infecciones mucocutáneas o sistémicas en el hombre y algunas especies animales. Asimismo de levaduras: Cryptococcus neoformans, agente etiológico

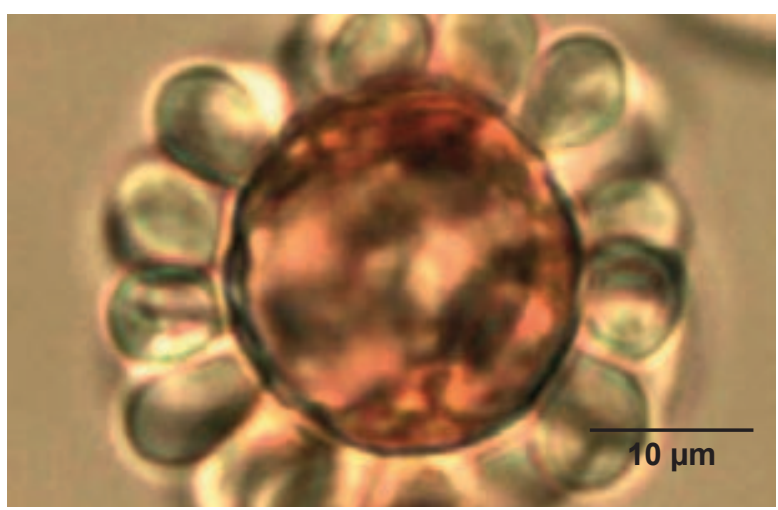

Figura 3. Paracoccidioides brasiliensis, examen en fresco de cultivo en agar sangre $\mathrm{BHI}$, teñido con safranina diluida al $0.1 \%$. Se observa levadura multigemante en timón de barco.

de la criptococosis, infección subaguda o crónica, principalmente del sistema nervioso central, que ingresa al organismo vía inhalatoria y rara vez por vía subcutánea, puede atacar el aparato respiratorio, además del sistema nervioso, piel, mucosa, ganglios linfáticos, huesos, etc. El $P$. brasiliensis, en su fase micelial esporógena, se encuentra en el suelo, fragmentos vegetales, espinas, etc. $y$ en su fase de levadura en tejidos infectados; agente causal de la paracoccidioidomicosis (blastomicosis sudamericana), infección crónica, granulomatosa de la piel, mucosas, ganglios y vísceras. El H. capsulatum, en su fase micelial se encuentra principalmente en compuestos nitrogenados: excretas de aves (gallina, lechuza), así como en excremento de murciélagos; en su fase levaduriforme se encuentra en tejidos infectados y es el agente causal de histoplasmosis que afecta principalmente el aparato respiratorio, con resolución espontánea sin tratamiento en pacientes inmunocompetentes. La histoplasmosis diseminada intensa aparece en ciertos pacientes infectados, lactantes, ancianos y pacientes

Servicio de Microbiología, Instituto Nacional de Salud del Niño. Lima, Perú.

Instituto de Medicina Tropical “Daniel A. Carrión”, Universidad Nacional Mayor de San Marcos. Lima, Perú.

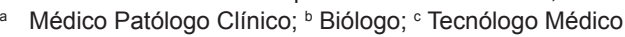

Recibido: 28-11-11 Aprobado: 07-12-11 


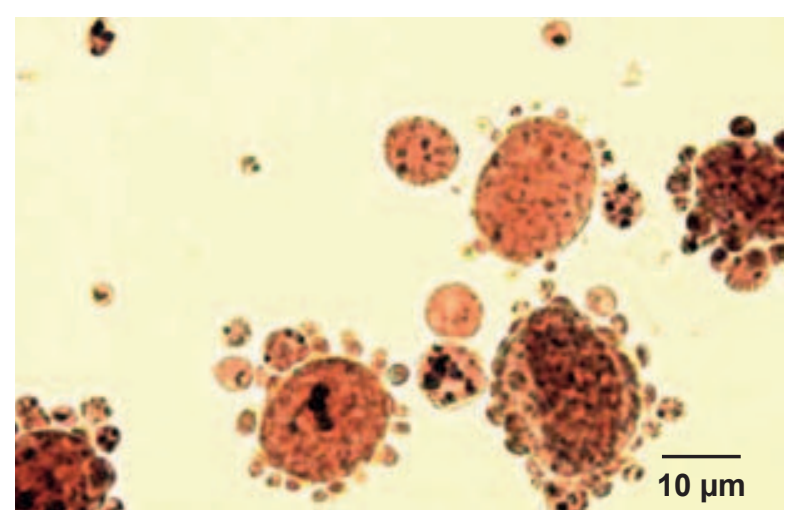

Figura 4. Paracoccidioides brasiliensis, microfotografía a partir de cultivo en chromo agar. Se observa cinco levaduras en timón de barco

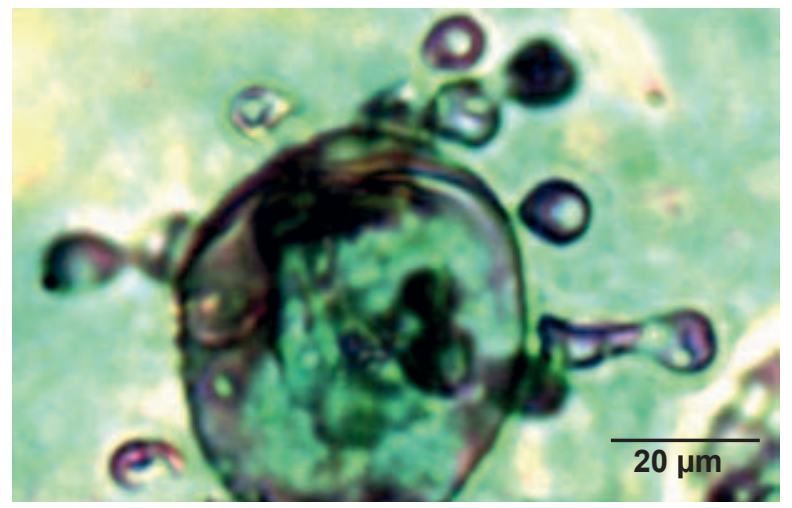

Figura 5. Paracoccidioides brasiliensis, microfotografía a partir de secreción de ganglio. Se observa levadura multigemante en timón de barco. Tinción con metenamina de plata.

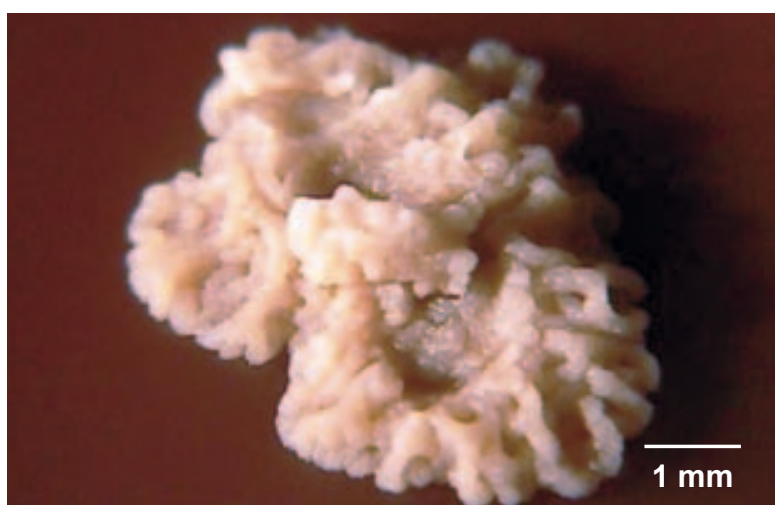

Figura 6. Paracoccidioides brasiliensis, fotografía de cultivo en agar sangre $\mathrm{BHI}{ }^{\circ} 35^{\circ} \mathrm{C}$; se observa colonia cerebriforme.

inmunodeprimidos o con SIDA. El diagnóstico de laboratorio de infecciones por hongos dimórficos se realiza con el estudio de las muestras clínicas: examen directo, con $\mathrm{KOH}$ al $20 \%$, calcoflúor, Giemsa, Gram, Ziehl Neelsen y en preparaciones histopatológicas incluyendo PAS y tinciones argénticas (metenamina de plata); el cultivo en medios como el agar sabouraud glucosado,

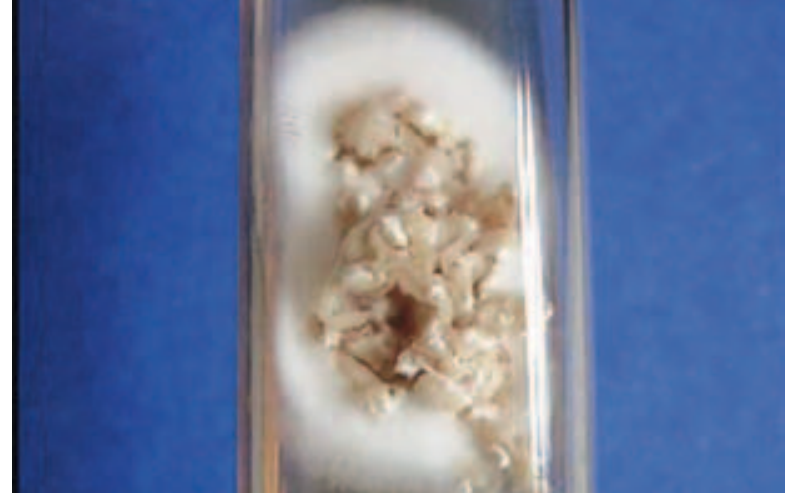

Figura 7. Paracoccidioides brasiliensis, fotografía de cultivo en agar Sabouraud glucosado a $35^{\circ} \mathrm{C}$. Se observa colonia cerebriforme rodeado de desarrollo de la forma filamentosa.

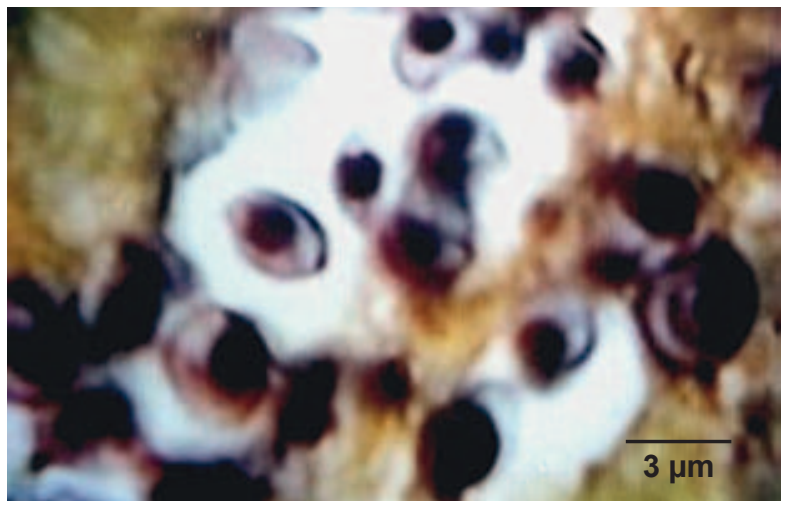

Figura 8. Histoplasma capsulatum, microfotografía a partir de biopsia de ganglio; se observa levaduras con pseudocápsula. Tincíón con metanamina de plata.

en agar $\mathrm{BHI}$ incubados a dos temperaturas: 25 y $36{ }^{\circ} \mathrm{C}$. El $H$. capsulatum al examen directo, en frotises o cortes histopatológicos, se observa como nidos de levaduras de 1 a $3 \mu \mathrm{m}$ intracelulares, incluidas en polimorfonucleares o histiocitos y en cultivo en agar Sabouraud colonias de color blanco de aspecto velloso, microscópicamente teñidas con azul de lactofenol las macroconidias tuberculadas características. El $P$. brasiliensis en el examen en fresco con $\mathrm{KOH}$ o coloreadas, en cortes histopatológicos se observa como levaduras esféricas u ovaladas de 10 a 80um con membrana engrosada y multigemantes (timón de barco); en cultivo en el medio agar $\mathrm{BHI}$ a $36{ }^{\circ} \mathrm{C}$, se observan colonias cerebriformes. El C. neoformans se presenta en microfotografía de preparación de LCR de pacientes con meningitis, con la técnica de tinta china modificada y cultivos en agar Sabouraud glucosado, así como en agar tabaco.

En la galería se presentan imágenes especiales de estos hongos, obtenidas de material de pacientes con enfermedades producidas por los agentes mencionados, en el Instituto Nacional de Salud del Niño y los atendidos en el Instituto de Medicina Tropical Daniel A. Carrión de 


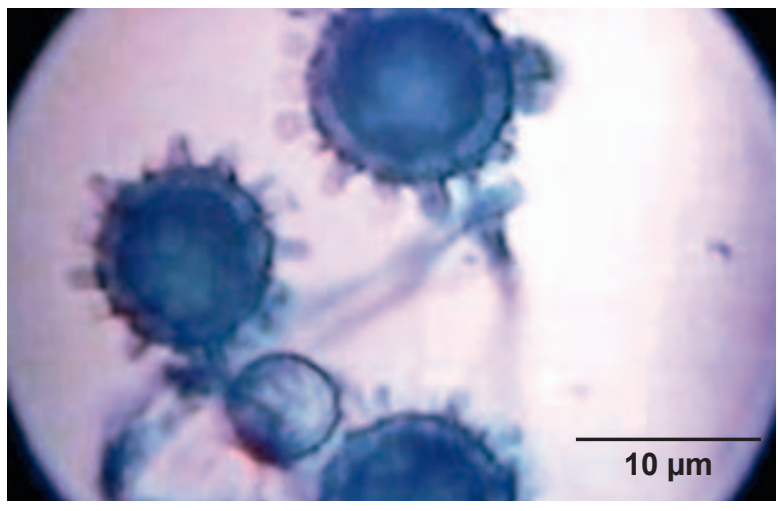

Figura 9. Histoplasma capsulatum, microfotografía a partir de cultivo en agar Sabouraud a temperatura ambiental; se visualiza macroconidias tuberculadas. Tinción con azul de lactofenol.

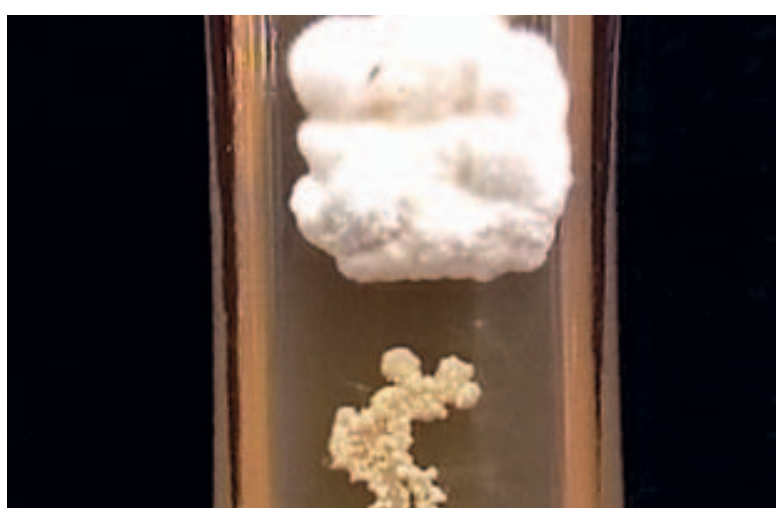

Figura 10. Histoplasma capsulatum, fotografía de cultivo en Agar Sabouraud glucosado a $35^{\circ} \mathrm{C}$. Se observa colonia de la fase levaduriforme en la parte inferior y filamentosa en la parte superior.

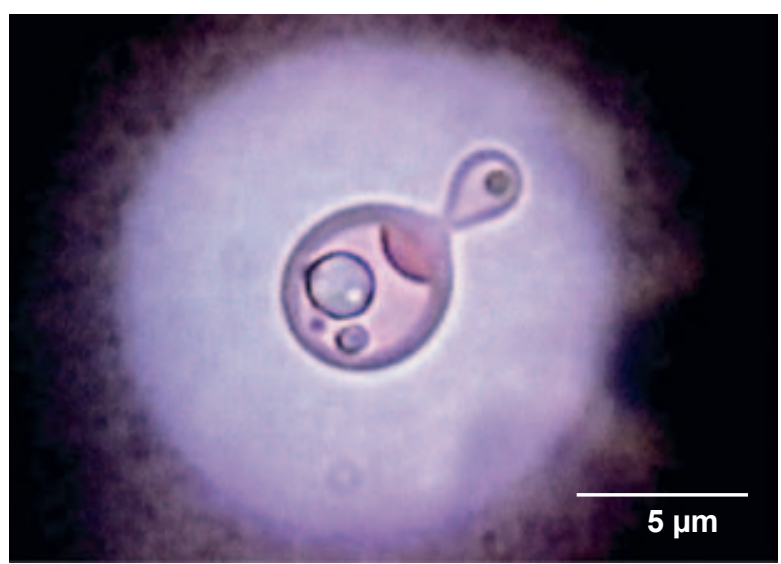

Figura 11. Cryptococcus neoformans, microfotografía en muestra de LCR con la técnica de tinta china modificada.

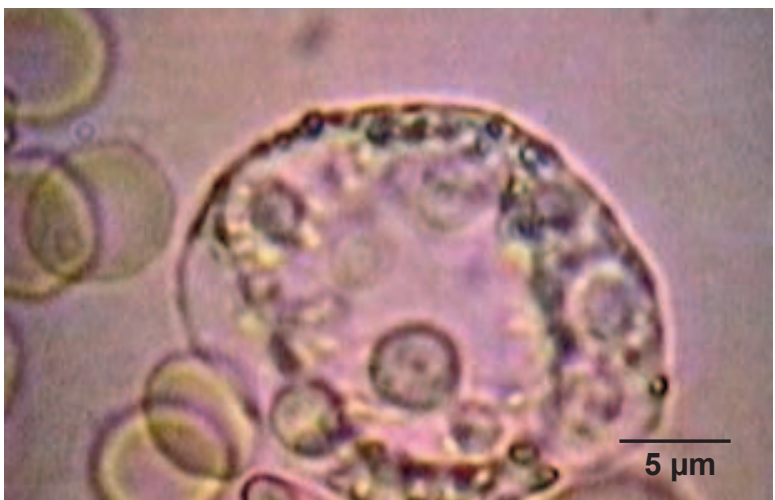

Figura 12. Cryptococcus neoformans, microfotografía en muestra de sangre en montaje húmedo. Se observa levadura gemante al centro de un leucocito.

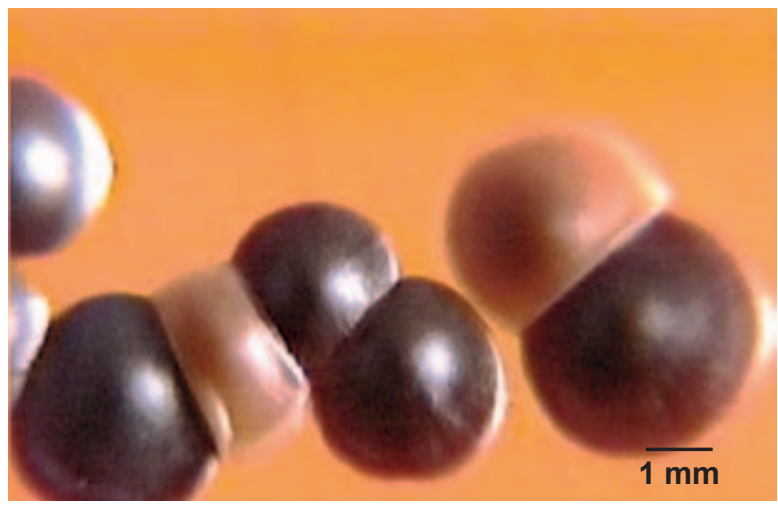

Figura 13. Cryptococcus neoformans, fotografía de cultivo en Agar tabaco, se observa colonias de color marrón a negro.

la Universidad Nacional Mayor de San Marcos. Estas imágenes, pueden ser de utilidad para el diagnóstico microbiológico en el laboratorio clínico, en la docencia y en la investigación.

\section{REFERENCIAS BIBLIOGRÁFICAS}

1. Burstein Alva Z. Aspectos clínicos de la Blastomicosis sudamericana (Paracoccidioidomicosis) en el Perú. Rev Peru Med Exp Salud Publica. 2002;19(1):43-47.

2. Zerpa R, Huicho L, Guillén A. Modified indian ink preparation for Cryptococcus neoformans in cerebrospinal fluids. J Clin Microbiol. 1996;34(9):2290-91.

Correspondencia: Rito Zerpa Larrauri

Dirección: Av. Rio Marañón 436, Los Olivos. Lima, Perú.

Teléfono: (511) 5286004

Correo electrónico: rzerpa43@yahoo.com 